\title{
Proximate composition, sensory evaluation and microbial quality of a dairy product (Special Kheersa) formulated with psyllium husk and malta peel powder
}

\author{
${ }^{1}$ Mamun, A.A., ${ }^{2 *}$ Matin, A. and ${ }^{2}$ Badsha, M.R. \\ ${ }^{1}$ Department of Applied Food Science and Nutrition, Chattogram Veterinary and Animal Sciences \\ University, Khulshi, Chattogram-4225, Bangladesh \\ ${ }^{2}$ Department of Food Processing and Engineering, Chattogram Veterinary and Animal Sciences University, \\ Khulshi, Chattogram-4225, Bangladesh
}

\author{
Article history: \\ Received: 30 December 2019 \\ Received in revised form: 20 \\ April 2020 \\ Accepted: 23 April 2020 \\ Available Online: 7 May \\ 2020
}

\section{Keywords:}

Special Kheersa,

Product development,

Proximate composition,

Microbial quality,

Sensory evaluation.

\section{DOI:}

https://doi.org/10.26656/fr.2017.4(6).425

\begin{abstract}
The research study was conducted to develop a suitable formulation of dairy products (Special Kheersa) using fresh cow milk with sugar and other ingredients such as psyllium husk, bread crumb, and malta peel powder in different proportions. Among four types of formulation, no psyllium husk and malta peel powder were used in Formulation (F1), but in Formulation (F2) $1.5 \mathrm{~g}$ psyllium husk and $30 \mathrm{~g}$ malta peel powder, Formulation (F3) 2.5 g psyllium husk and $30 \mathrm{~g}$ malta peel powder, Formulation (F4) $5 \mathrm{~g}$ psyllium husks and 30 g malta peel powder were used respectively. This study also assessed the proximate composition, sensory attributes and microbial quality of the Special Kheersa formulated with psyllium husk and malta peel powder. The results of the proximate analysis showed a significant difference $(p<0.05)$ in all parameters. Special Kheersa prepared with $2.5 \mathrm{~g}$ of psyllium husk and $30 \mathrm{~g}$ of malta peel powder showed the maximum sensory score. Total viable count, Coliform, E. coli and Salmonella count of the Special Kheersa were determined after 0, 24, 48 and $72 \mathrm{hrs}$ of its preparation. The formulated Special Kheersa is nutritionally acceptable like commercially available kheer and sufficient to meet the nutritional requirements as a dessert item.
\end{abstract}

\section{Introduction}

Cow milk and milk products are a good source of all types of nutrients. Cow milk contains about $86 \%$ water, $4.65 \%$ fat, $3.4 \%$ protein, $4.6 \%$ lactose, and $0.54 \%$ minerals (Smith et al., 2005). Milk is essential for the physical and mental development of humans. It is also crucial for bone growth, tooth growth, heart activity, and all body functions. Cow milk destroys harmful digestive system microbes and promotes beneficial bacteria. Cow milk contains lactose sugar which is an essential source of energy. Milk is vital for all ages, a group of people viz. infant, adults, and old person (Bowlby, 1958). Milk of cow is used for the preparation of different dairy products as Cheese, Khoa (Mava), Yoghurt, Lassi (Buttermilk), Kulfi, Khoya, Rabri, Kheer, Srikhand, Basundi, Condensed milk, powdered milk, toned milk, double toned milk etc. Dairy products are generally defined as food products that are mainly produced from milk. Kheersa is a semisolid-to-fluid dairy product with partially disintegrated cooked rice grains dispersed in a viscous liquid comprising soluble starch from rice grains.
Conventionally prepared kheersa has a dark creamy color as a result of prolonged cooking of rice grains in milk, which generally takes approximately one hour (Arora and Patel, 2017).

Kheersa is made by concentrating milk with the simultaneous cooking of rice grains and the addition of sugar during the process. In spite of its religious value, nutritional significance and commercial potential, these products remain to confine to domestic kitchens. One of the reasons for the lack of it's organized manufacture and marketing is reduced shelf-life and lack of technology for large-scale production (Jha et al., 2011).

Though Kheersa is a tasty and delicious dairy dessert item, considering its food value and self-life, it has some drawbacks on health effects. For this reason, I try my best to increase the food value-adding psyllium husk and malta peel powder which is health effective. Malta peel powder also increases fiber content by giving the natural color and flavor of the product (Ojha and Thapa, 2017). Psyllium husk is associated with cardiovascular risk 
reduction through multiple mechanisms, and consuming a variety of cereal fibers sources offer health benefits specific to the source (Bernstein et al., 2013). Certain cereal fibers have been studied more extensively than others and provide greater support for their assimilation into a healthful diet. $\beta$-glucan from oats or barley, or a mixture of the whole oats and barley, and soluble fiber from psyllium diminishes the risk of coronary heart disease; inulin-type fructans added to foods and beverages may modestly decrease serum triacylglycerols; arabinoxylan and resistant starch may recover glycemic control. Individuals with low cereal fiber intake should upsurge their intake of whole grains to receive the benefits of the whole grains in the count to fiber. For those regulating to the texture and palatability of the whole grains, turning to added-fiber products rich in $\beta$-glucan and psyllium may permit them to reach their fiber goals without increasing caloric intake (Kaur, 2011). Dietary fiber intake provides many health benefits. Individuals with high consumptions of dietary fiber appear to be at significantly lower risk for developing coronary heart disease, stroke, hypertension, diabetes, obesity, and certain gastrointestinal diseases. Increasing fiber consumption lowers blood pressure and serum cholesterol levels. Increased intake of soluble fiber improves glycemia and insulin sensitivity in nondiabetic and diabetic individuals (Hanai et al., 1997). Fiber supplementation in weighty individuals significantly enhances weight loss. Prebiotic fibers appear to enhance immune function. Dietary fiber intake provides similar benefits for children as for adults (Anderson et al., 2009). The recommended dietary fiber intakes for children and adults are $14 \mathrm{~g} / 1000 \mathrm{kcal}$ (Williams et al., 1995). More effective communication and consumer education is required to enhance fiber consumption from foods or supplements (Kaczmarczyk et al., 2012). So, the objectives of this study were to formulate Special Kheersa with psyllium husk and Malta peel powder and assess the composition, and overall acceptability of the developed product.

\section{Materials and methods}

\subsection{Collection of raw materials}

The raw cow milk, powdered milk, sugar, psyllium husk, bread crumb, malta fruits, pistachio nut and other ingredients were purchased from the local market and super shop of Chattogram.

\subsection{Development of Special Kheersa}

\subsubsection{Preparation of malta peel powder}

For the preparation of malta peel powder, at first fresh malta was washed by clean water. Then the juice of malta was extracted, and then the peel was collected for the further function. The peel was cut into small pieces and blanch for 5 mins to inactive the enzymatic function. Then the peel was placed in-tray and kept in the cabinet dryer (Genlab $1000-\mathrm{L}, \mathrm{UK}$ ) at $60^{\circ} \mathrm{C}$ for $24 \mathrm{hrs}$. Finally, the dried malta peel was ground into a fine powder by using a mixer grinder (Panasonic MX-AC300). The peel powder was packed in the poly bag and storage in the refrigerator for further use.

\subsubsection{Formulation and processing of Special Kheersa}

Various trials were carried out to formulate the product. Finally, the formulation of Special Kheersa, according to Table 1. At first, the cow milk, powdered milk, sugar, and pistachio nut was boiled for 30 mins to make it concentrate up to $200^{\circ}$ Brix. Then the required amount of bread crumb, psyllium husk was added. Then it was heated to make it concentrated up to $400^{\circ}$ Brix (Jha et al., 2011). In the last stage, malta peel powder was added to the product, which gives an attractive color and flavor of the product. After cooling the product was ready for consumption.

Table 1. Formulation of Special Kheersa

\begin{tabular}{|c|c|c|c|c|}
\hline Ingredients & 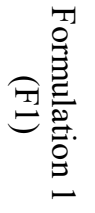 & 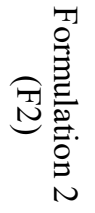 & 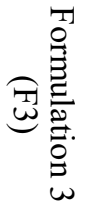 & 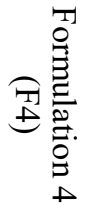 \\
\hline Raw cow milk & $1 \mathrm{~L}$ & $1 \mathrm{~L}$ & $1 \mathrm{~L}$ & $1 \mathrm{~L}$ \\
\hline Powdered milk & $75 \mathrm{~g}$ & $75 \mathrm{~g}$ & $75 \mathrm{~g}$ & $75 \mathrm{~g}$ \\
\hline Sugar & $110 \mathrm{~g}$ & $110 \mathrm{~g}$ & $110 \mathrm{~g}$ & $110 \mathrm{~g}$ \\
\hline Psyllium husk & - & $1.5 \mathrm{~g}$ & $2.5 \mathrm{~g}$ & $5 \mathrm{~g}$ \\
\hline Bread crumb & $50 \mathrm{~g}$ & $50 \mathrm{~g}$ & $50 \mathrm{~g}$ & $50 \mathrm{~g}$ \\
\hline Malta peel Powder & - & $30 \mathrm{~g}$ & $30 \mathrm{~g}$ & $30 \mathrm{~g}$ \\
\hline Pistachio nut & $20 \mathrm{~g}$ & $20 \mathrm{~g}$ & $20 \mathrm{~g}$ & $20 \mathrm{~g}$ \\
\hline
\end{tabular}

\subsection{Quality evaluation of Special Kheersa}

\subsubsection{Proximate analysis of Special Kheersa}

The proximate composition of Special Kheersa was determined using methods described by the Association of Official Analytical Chemists (AOAC, 2000). The samples were analyzed for moisture, ash, crude protein, crude fiber, crude fat, and carbohydrate. The carbohydrate content of the sample was estimated as the difference obtained after subtracting the values of protein, fat, ash, and fiber from the total dry matter. It was given as the difference between 100 and a total of other proximate components. Hence, it was calculated using the formula below:

$\% \mathrm{CHO}=100 \%-\%($ Protein + Fat + fiber + Ash + Moisture content).

The energy value of the samples was determined by multiplying the protein content by 4 , carbohydrate 
content by 4 , and fat content by 9 according to standard James formula (James, 1995).

Energy Value $=($ Crude protein $\times 4)+($ Total carbohydrate $\times 4)+($ Crude fat $\times 9)$.

All analyses were performed in triplicate.

\subsubsection{Sensory evaluation}

Descriptive terms were given to various qualities attributes like appearance, color, flavor, consistency, and general acceptance (Larmond, 1977). Nine-point Hedonic scales was arranged such that: Like extremely $=$ 9 , Like very much $=8$, Like moderately $=7$, Like slightly $=6$, Neither like nor dislike $=5$, Dislike slight $=$ 4, Dislike moderately $=3$, Dislike very much $=2$, Dislike Extremely $=1$. While scoring, the highest score (9) was assigned to the most preferred characteristic and least score (1) to the least desired characteristic. The four samples were presented to 10 panelists in the laboratory of the Department of Food Processing and Engineering, Chattogram Veterinary and Animal Sciences University (CVASU).

\subsubsection{Microbiological evaluation of Special Kheersa}

The total viable count was measured by using plate count agar medium according to a standard procedure (Atallah, 2015). The enumeration of bacteria was performed using the digital colony counter, and the result was expressed as colony-forming units per $\mathrm{mL}$ (CFU/ $\mathrm{mL}$ ). Total coliform and $E$. coli count was done according to Standard Methods (Pitkanen et al., 2007). The most probable number of coliforms per milliliter or per gram of sample (i.e., the MPN) was calculated from the number of tubes in the new series showing gas formation.

\subsection{Statistical analysis}

Data was stored in Microsoft Excel 2013 and then exported into Statistical Package for Social Science (SPSS 16th version) for statistical analysis. Descriptive analysis was performed by using mean and standard deviation for different variables. Finally, one-way ANOVA and posthoc tests were used to identify the variation within the sample groups. The statistical analysis was conducted for a 5\% level of significant $(\mathrm{p}<0.05)$.

\section{Results and discussion}

\subsection{Proximate composition of Special Kheersa}

Proximate composition is an utmost integral part of a food product. Table 2 shows the proximate composition of four formulated Special Kheersa. The results of moisture content ranged from $60.3-64.6 \%$ for different type formulated Special Kheersa. The highest value of moisture content $(64.6 \pm 0.06 \%)$ was found in F1 formulated Special Kheersa, and the lowest value $(60.3 \pm 0.2 \%)$ was for F4 formulation of Special Kheersa. In the case of Moisture content, a one-way ANOVA showed that the samples were significantly different $(p<0.05)$. The moisture content of the Special Kheersa decreased with the addition of psyllium husk and malta peel powder in the blend. The decrease in moisture content with an increase in total solids was also observed in Kashmiri saffron phirini and rice kheer (Srinivasan and Anantakrishna, 1964; Bhat et al., 2010). Results recorded are similar to the findings of Adil et al. (2017), who observed that with the increase in the proportion of pumpkin powder and skim milk powder in the blend, the average moisture content of reconstituted Kheer was decreased. Moisture content is an important factor in maintaining food quality because increase moisture facilitates the growth of microbes and ultimately destroy quality in a short time. Quality of Special Kheersa remains excellent up to $16 \mathrm{hrs}$ in room temperature $\left(25^{\circ}\right.$ $\mathrm{C})$, and in chilling condition $\left(5^{\circ} \mathrm{C}\right)$, it can be stored for 0 to 3 days.

The outcomes of Ash content ranged from 1.38$2.15 \%$ for different type formulated Special Kheersa. The highest value of moisture content $(2.15 \pm 0.01 \%)$ was found in F4 formulated Special Kheersa and the lowest

Table 2. Proximate analysis of Special Kheersa

\begin{tabular}{lccccc}
\hline \multirow{2}{*}{\multicolumn{1}{c}{ Parameter }} & \multicolumn{5}{c}{ Formulation } \\
\cline { 2 - 5 } & \multicolumn{1}{c}{$\mathrm{F} 1$} & $\mathrm{~F} 2$ & $\mathrm{~F} 3$ & $\mathrm{~F} 4$ & Level of sign. \\
\hline Moisture (\%) & $64.6 \pm 0.06^{\mathrm{a}}$ & $62.4 \pm 0.15^{\mathrm{b}}$ & $61.4 \pm 0.10^{\mathrm{c}}$ & $60.3 \pm 0.2^{\mathrm{d}}$ & $* *$ \\
Ash (\%) & $1.38 \pm .02^{\mathrm{d}}$ & $1.76 \pm 0.01^{\mathrm{c}}$ & $1.97 \pm .02^{\mathrm{b}}$ & $2.15 \pm 0.01^{\mathrm{a}}$ & $* *$ \\
Protein (\%) & $5.4 \pm 0.10^{\mathrm{a}}$ & $4.8 \pm 0.07^{\mathrm{b}}$ & $4.7 \pm 0.05^{\mathrm{bc}}$ & $4.5 \pm 0.15^{\mathrm{d}}$ & $*$ \\
Fat (\%) & $8.4 \pm 0.02^{\mathrm{a}}$ & $7.9 \pm 0.02^{\mathrm{b}}$ & $7.7 \pm 0.01^{\mathrm{c}}$ & $7.5 \pm 0.03^{\mathrm{d}}$ & $* *$ \\
Fiber (\%) & $2.9 \pm .03^{\mathrm{d}}$ & $3.7 \pm 0.02^{\mathrm{c}}$ & $4.1 \pm 0.03^{\mathrm{b}}$ & $4.5 \pm 0.05^{\mathrm{a}}$ & $* *$ \\
Carbohydrate (\%) & $17.4 \pm 0.02^{\mathrm{d}}$ & $19.2 \pm 0.02^{\mathrm{c}}$ & $20.1 \pm 0.03^{\mathrm{b}}$ & $21.2 \pm 0.02^{\mathrm{a}}$ & $* *$ \\
Energy (kcal/100 g) & $166.09 \pm 0.03^{\mathrm{d}}$ & $167.69 \pm 0.04^{\mathrm{c}}$ & $168.86 \pm 0.02^{\mathrm{b}}$ & $169.73 \pm 0.04^{\mathrm{a}}$ & $* *$ \\
\hline
\end{tabular}

** Significant at $\mathrm{P}<0.01$; * Significant at $\mathrm{P}<0.05$; Values followed by different superscript letters denote a significant difference; comparison is done across formulation. 
value $(1.38 \pm 0.02 \%)$ was for $\mathrm{F} 1$ formulation of Special Kheersa. In the case of Ash content, a one-way ANOVA showed that the samples were significantly different $(p<0.05)$. Ash content of the Special Kheersa increased with the addition of psyllium husk and malta peel powder in the blend. The ash contents of the Special Kheersa was higher than reported by Adil et al. (2017) for pumpkin-based reconstituted Kheer and lower values observed by Rather et al. (2012) for Semolina Milk Pudding-Kashmiri Fireen.

The results of Protein content ranged from 4.5-5.4\% for different type formulated Special Kheersa. The highest value of Protein content $(5.4 \pm 0.10 \%)$ was found in F1 formulated Special Kheersa, and the lowest value $(4.5 \pm 0.15 \%)$ was for F4 formulation of Special Kheersa. In the case of protein content, a one-way ANOVA showed that the samples were significantly different $(p<0.05)$. It can be observed from Table 2 that values for protein decrease slightly with the increase in the proportion of psyllium husk and malta peel powder. The results of the Protein content of the Special Kheersa was a close agreement with Adil et al. (2017) for pumpkinbased reconstituted Kheer and Usha et al. (2010) for instant dhokla mix with the incorporation of pumpkin flour.

The results of Fat content ranged from $7.5-8.4 \%$ for different type formulated Special Kheersa. The highest value of fat content $(8.4 \pm 0.02 \%)$ was found in $\mathrm{F} 1$ formulated Special Kheersa, and the lowest value $(7.5 \pm 0.03 \%)$ was for the F4 formulation of Special Kheersa. In the case of Fat content, a one-way ANOVA showed that the samples were significantly different $(p<0.05)$. It can be observed from Table 2 that values for fat content decrease slightly with the increase in the proportion of psyllium husk and malta peel powder. The fat content of Special Kheersa was higher than reported by Adil et al. (2017) for pumpkin-based reconstituted Kheer, Changade et al. (2012) for fresh pumpkin kheer and Rather et al. (2012) for Semolina Milk PuddingKashmiri Fireen.

The outcomes of fiber content ranged from 2.9-4.5\% for different type formulated Special Kheersa. The highest value of fiber content $(4.5 \pm 0.05 \%)$ was found in F4 formulated Special Kheersa, and the lowest value $(2.9 \pm 0.03 \%)$ was for F1 formulation of Special Kheersa. In the case of fiber content, a one-way ANOVA showed that the samples were significantly different $(p<0.05)$. The fiber content of Special Kheersa became higher due to the addition of psyllium husk, malta peel powder, bread crumb, and pistachio nut. Because, good sources of dietary fiber include whole grains, fruits and vegetables, as well as nuts and legumes. The fiber in food has been shown to reduce the risk of various medical conditions (Franceschi et al., 2001). The suggested benefits of fiber are to reduce breast cancer, type-2 diabetes, obesity, diverticular disease, hyperlipidemia or high blood cholesterol.

The results of carbohydrate content ranged from 17.4 $-21.2 \%$ for different type formulated Special Kheersa. The highest value of carbohydrate content of $(21.2 \pm 0.02 \%)$ was found in F4 formulated Special Kheersa, and the lowest value of $(17.4 \pm 0.02 \%)$ was for the F1 formulation of Special Kheersa. In the case of carbohydrate content, a one-way ANOVA showed that the samples were significantly different $(p<0.05)$. Due to the addition of psyllium husk, malta peel powder, bread crumb, and pistachio nut carbohydrate content become slightly high. An increasing trend in carbohydrate content was also observed in kheer with the increase in the number of cereals used in its manufacture (De et al., 1976).

Total energy obtains from $100 \mathrm{~g}$ Special Kheersa is $168.86 \mathrm{kcal}$. The results of energy value ranged from $166.09(\mathrm{kcal} / 100 \mathrm{~g})$ to $169.73(\mathrm{kcal} / 100 \mathrm{~g})$ for different type formulated Special Kheersa. The highest value of energy content $169.73 \pm 0.04(\mathrm{kcal} / 100 \mathrm{~g})$ was found in F4 formulated Special Kheersa, and the lowest value $166.09 \pm 0.03(\mathrm{kcal} / 100 \mathrm{~g})$ was for $\mathrm{F} 1$ formulation of Special Kheersa. The results of the energy value showed that the samples were significantly different $(p<0.05)$.

\subsection{Sensory evaluation of Special Kheersa}

Sensory evaluation is an integral part of the quality evaluation of a product. The Special Kheersa was subjected to sensory evaluation by semi-trained panel of judges using the 9-point hedonic scale. In the sensory evaluation of prepared four formulations of Special Kheersa, i.e. F1, F2, F3 and F4. The sensory scores of Special Kheersa were presented in Table 3. There was a significant difference $(\mathrm{p}<0.05)$ in all the sensory parameters assessed. The mean score of appearance increased from 5.7 to 8.0 for different types of formulated Special Kheersa. The highest score of appearance $(8.0 \pm 0.66)$ was found in F3 formulated Special Kheersa and the lowest value $(5.7 \pm 0.67)$ was for F1 formulation of Special Kheersa. In the case of a score of appearance, a one-way ANOVA showed that the samples were significantly different $(p<0.05)$. For the addition of Malta peel powder, the appearance of the product was so kind and attractive. Adil et al. (2017) reported the appearance score as 7.24 to 6.40 for pumpkin-based Kheer.

The mean score of color increased from 5.5 to 8.4 for different types of formulated Special Kheersa. The 
Table 3. Sensory evaluation of Special Kheersa

\begin{tabular}{lccccc}
\hline \multirow{2}{*}{ Sensory Attributes } & \multicolumn{5}{c}{ Formulation } \\
\cline { 2 - 5 } & F1 & F2 & F3 & F4 & Level of sign. \\
\hline Appearance & $5.7 \pm 0.67^{\mathrm{c}}$ & $7.1 \pm 0.56^{\mathrm{b}}$ & $8.0 \pm 0.66^{\mathrm{a}}$ & $7.5 \pm 0.84^{\mathrm{ab}}$ & $* *$ \\
Color & $5.5 \pm 0.85^{\mathrm{b}}$ & $8.1 \pm 0.57^{\mathrm{a}}$ & $8.4 \pm 0.52^{\mathrm{a}}$ & $7.8 \pm 0.63^{\mathrm{a}}$ & $* *$ \\
Flavor & $5.8 \pm 1.03^{\mathrm{b}}$ & $7.8 \pm 0.78^{\mathrm{a}}$ & $8.2 \pm 0.63^{\mathrm{a}}$ & $7.5 \pm 0.52^{\mathrm{a}}$ & $* *$ \\
Consistency & $6.8 \pm 0.63^{\mathrm{a}}$ & $7.5 \pm 0.53^{\mathrm{a}}$ & $7.5 \pm 0.71^{\mathrm{a}}$ & $7.3 \pm 0.48^{\mathrm{a}}$ & $*$ \\
Overall acceptability & $5.9 \pm 0.74^{\mathrm{b}}$ & $7.5 \pm 0.53^{\mathrm{a}}$ & $8.0 \pm 0.67^{\mathrm{a}}$ & $7.5 \pm 0.52^{\mathrm{a}}$ & $* *$ \\
\hline
\end{tabular}

** Significant at $\mathrm{p}<0.01$; Significant at $\mathrm{p}<0.05$; Values followed by different superscript letters denote a significant difference; comparison is done across formulation.

highest score of color $(8.4 \pm 0.52)$ was found in F3 formulated Special Kheersa and the lowest value (5.5 \pm 0.85$)$ was for the F1 formulation of Special Kheersa. In the case of a score of color, a one-way ANOVA showed that the samples were significantly different $(p<0.05)$. It may be due to the addition of malta peel powder, which gave it a unique and attractive color. Adil et al. (2017) prepared kheer from pumpkin, Shreeja et al. (2019) prepared Payasam from Germinated Buckwheat Milk and Mukhekar et al. (2019) prepared kheer from rice reported the color score as 6.88 to 7.40 , 7.46 to 8.66 and 7.25 to 8.75 .

The mean score of flavors increased from 5.8 to 8.2 for different types of formulated Special Kheersa. The highest score of flavors $(8.2 \pm 0.63)$ was found in F3 formulated Special Kheersa, and the lowest value (5.8 \pm 1.03$)$ was for the F1 formulation of Special Kheersa. In the case of a score of flavors, a one-way ANOVA showed that the samples were significantly different $(p<0.05)$. The addition of malta peel powder and pistachio nut gave the desirable flavor of the product. Adil et al. (2017) prepared kheer from pumpkin, Shreeja et al. (2019) prepared Payasam from Germinated Buckwheat Milk and Mukhekar et al. (2019) prepared kheer from rice reported the flavor score as 6.64 to 7.32 , 7.13 to 8.46 and 6.75 to 8.63 .

The mean score of consistency increased from 6.8 to 7.5 for different types of formulated Special Kheersa. The highest score of consistency (7.5 \pm 0.71 ) was found in F3 formulated Special Kheersa, and the lowest value $(6.8 \pm 0.63)$ was for the F1 formulation of Special Kheersa. In the case of a score of consistency, a one-way ANOVA showed that the samples were significantly different $(p<0.05)$. The addition of psyllium husk and pistachio nut gave the desirable mouthfeel and increased the fiber content of the product.

The mean score of overall acceptability increased from 5.9 to 8.0 for different type formulated Special Kheersa. The highest score of overall acceptability $(8.00 \pm 0.67)$ was found in F3 formulated Special Kheersa, and the lowest value $(5.9 \pm 0.74)$ was for the F1 formulation of Special Kheersa. In the case of a score of overall acceptability, a one-way ANOVA showed that the samples were significantly different $(\mathrm{p}<0.05)$. In all parameters, Formulation F3 (2.5 g of psyllium husk and $30 \mathrm{~g}$ of malta peel powder) had the highest acceptance rate. It may be due to the addition of an adequate proportion of psyllium husk and malta peel powder, which made it unique among all formulation. Adil et al. (2017) prepared kheer from pumpkin, Shreeja et al. (2019) prepared Payasam from Germinated Buckwheat Milk, Narwade et al. (2003) prepared kheer from safflower milk blended with buffalo milk with different level of sugar and Mukhekar et al. (2019) prepared kheer from rice reported the overall acceptability score as 6.40 to $7.30,6.86$ to $8.66,5.44$ to 8.55 and 6.96 to 8.33 .

\subsection{Microbiological evaluation of the Special Kheersa}

Microbiological attributes are pointers of security, quality and timeframe of realistic usability of the developed Special Kheersa. The results on the Total viable count, E. coli, and Salmonella of the Special Kheersa after $0,24,48$, and $72 \mathrm{hrs}$ of its preparation are given in Table 4. Total viable count of F1 was $1.7 \times 10^{2}$ $\mathrm{CFU} / \mathrm{g}$ at $0 \mathrm{hr}$ and increased up to $1.6 \times 10^{4} \mathrm{CFU} / \mathrm{g}$ at 72 hrs, F2 was $1.6 \times 10^{2} \mathrm{CFU} / \mathrm{g}$ at $0 \mathrm{hr}$ and increased up to $1.3 \times 10^{4} \mathrm{CFU} / \mathrm{g}$ at $72 \mathrm{hrs}, \mathrm{F} 3$ was $1.8 \times 10^{2} \mathrm{CFU} / \mathrm{g}$ at 0 $\mathrm{hr}$ and increased up to $1.5 \times 10^{4} \mathrm{CFU} / \mathrm{g}$ at $72 \mathrm{hrs}$, F4 was $1.2 \times 10^{2} \mathrm{CFU} / \mathrm{g}$ at $0 \mathrm{hr}$ and increased up to $1.3 \times 10^{4}$ $\mathrm{CFU} / \mathrm{g}$ at $72 \mathrm{hrs}$. During the time of the storage period, all the samples showed an increased total viable count. It may be due to no use of preservative and improper handling of the samples during the processing of the products. Adil et al. (2017) observed that TVC of Pumpkin based kheer was an initial 35.30 to $40.44 \times 10^{3}$ $\mathrm{CFU} / \mathrm{g}$ at the end of shelf life of 3 days in treatment $\mathrm{T} 1$ ( $1 \%$ pumpkin powder $+43 \%$ skim milk powder). Sarode et al. (2007) observed that TVC of Karad kheer was $2.892 \times 10^{3} \mathrm{CFU} / \mathrm{g}$, which increased to $14.20 \times 10^{3} \mathrm{CFU} /$ $\mathrm{g}$ and $48.40 \times 10^{3} \mathrm{CFU} / \mathrm{g}$ after third and fifteen hr of storage at $37^{\circ} \mathrm{C}$. In all cases, total coliform, E. coli, and Salmonella were not detected. After preparation, the product quality was right up to 3 days in chilling condition. After 3 days, the hygienic indicator organisms 
were gradually increased and the product quality became deteriorating. Unhygienic transportation and handling of milk and milk products, post preparation contamination, lack of personal and utensil hygiene and contaminated adulterated ingredients are the main features responsible for the microbial deterioration and contamination of the milk products (Anshu et al., 2014).

Table 4. Microbiological evaluation of the Special Kheersa

\begin{tabular}{|c|c|c|c|c|c|c|}
\hline \multirow{2}{*}{ 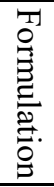 } & \multicolumn{4}{|c|}{ TVC } & \multirow{2}{*}{\begin{tabular}{l}
$\mathbb{1}$ \\
\multirow{2}{*}{}
\end{tabular}} & \multirow{2}{*}{ 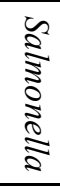 } \\
\hline & $0 \mathrm{hr}$ & $24 \mathrm{hrs}$ & $48 \mathrm{hrs}$ & $72 \mathrm{hrs}$ & & \\
\hline F1 & $1.7 \times 10^{2}$ & $1.8 \times 10^{3}$ & $1.9 \times 10^{3}$ & $1.6 \times 10^{4}$ & \multirow{4}{*}{ ND } & \multirow{4}{*}{ ND } \\
\hline $\mathrm{F} 2$ & $1.6 \times 10^{2}$ & $1.7 \times 10^{3}$ & $2.0 \times 10^{3}$ & $1.3 \times 10^{4}$ & & \\
\hline $\mathrm{F} 3$ & $1.8 \times 10^{2}$ & $1.6 \times 10^{3}$ & $1.8 \times 10^{3}$ & $1.5 \times 10^{4}$ & & \\
\hline F4 & $1.2 \times 10^{2}$ & $1.3 \times 10^{3}$ & $1.7 \times 10^{3}$ & $1.3 \times 10^{4}$ & & \\
\hline
\end{tabular}

$\mathrm{ND}=$ Not Detectable

\section{Conclusion}

This study has shown that the addition of psyllium husk and malta peel powder with cow milk improved the nutritional quality of the Special Kheersa. At the same time, the microbial presence of salmonella and E.coli growth was strictly prohibited. The use of Psyllium husk, malta peel powder, and pistachio nut improved the fiber quantity of the Special Kheersa. Special Kheersa produced from such composites will not only increase savings in foreign exchange for countries like us but also enhance the utilization of locally available cow milk and lead to improved nutrient intake by the consumer. Additional psyllium husk and malta peel powder increased the appearance, color and flavor of the developed product Special Kheersa which is health effective. Well, furnished dairy industries can accept new technology to further new product development and marketing.

\section{Conflict of interest}

The authors declare no conflict of interest.

\section{Acknowledgents}

Authors are highly thankful to Committee for Advanced Studies and Research (CASR), Chattogram Veterinary and Animal Sciences University, and Poultry Research and Training Center (PRTC) of Chattogram Veterinary and Animal Sciences University (CVASU) for institutional support and assistance.

\section{References}

Adil, S., Changade S.P., Dhotre A.V. and Datir R.P. (2017). A study on compositional characteristics of pumpkin based reconstituted Kheer. Indian Journal of Dairy Science, 70(1), 66-71.

Anderson, J.W., Baird, P., Davis, R.H., Ferreri, S., Knudtson, M., Koraym, A., Waters, V. and Williams, C.L. (2009). Health benefits of dietary fiber. Nutrition Reviews, 67(4), 188-205. https:// doi.org/10.1111/j.1753-4887.2009.00189.x

Anshu, S.C., Ritu, T., Harleen, C. and Ratika, K. (2014). Microbial quality evaluation of milk products. International Journal of Development Research, 4 (12), 2623-2628.

AOAC. (2000). Official methods of analysis. 17th ed. Maryland, USA: Association of Official Analytical Chemists.

Arora, S.K. and Patel, A. (2017). Effect of fiber blends, total solids, heat treatment, whey protein concentrate and stage of sugar incorporation on dietary fiberfortified Kheer. Journal of Food Science and Technology, 54, 3512-3520. https://doi.org/10.1111/ j.1753-4887.2009.00189.x

Atallah, A. (2015). Development of new functional beverages from milk permeate using some probiotic bacteria and fruits pulp. Egyptian Journal of Dairy Science, 43(1), 25-39.

Bernstein, A., Titgemeier, B., Kirkpatrick, K., Golubic, M. and Roizen, M. (2013). Major cereal grain fibers and psyllium in relation to cardiovascular health. Nutrients, 5(5), 1471-1487. https://doi.org/10.3390/ nu5051471

Bhat, Z.F., Pathak, V., Ahmed, S.R. and Bukhari, S.A.A. (2010). Development of Kashmiri saffron phirne from reconstituted skim milk. Beverage Food World, 37(1), 81-84.

Bowlby, J. (1958). The nature of the child's tie to his mother. International Journal of Psycho-analysis, $39,350-373$.

Changade, S.P., Wasnik, P.G., Waseem, M., Kadu, A.B. and Chapke, J.S. (2012), Storage studies of Bottle Gourd and Pumpkin kheer. Journal of Dairying Foods and Home Sciences, 31(2), 99-103.

De, S.K., Thomkinson, D.K., Gahlot, D.P. and Mathur, O.N. (1976). Studies on methods of preparation and preservation of kheer. Indian Journal of Dairy Sciences, 29(4), 316-318.

Franceschi, S., Masco, L.D., Augustin, L., Negri, E., Parpinel, M., Boyle, P., Jenkins, D. and Vecchia, C.L. (2001). Dietary glycemic load and colorectal cancer risk. Annals of Oncology, 12, 173-178. https://doi.org/10.1023/A:1008304128577

Hanai, H., Ikuma, M., Sato, Y., Iida, T., Hosoda, Y., Matsushita, I., Nogaki, A., Yamada, M. and Kaneko, E. (1997). Long-term effects of water-soluble corn 
bran hemicellulose on glucose tolerance in obese and non-obese patients: improved insulin sensitivity and glucose metabolism in obese subjects. Bioscience, Biotechnology and Biochemistry, 61(8), 1358-1361. https://doi.org/10.1271/bbb.61.1358

James, C.S. (1995). Analytical Chemistry of Foods. $1^{\text {st }}$ ed. New York: Blackie Academic and Professional. https://doi.org/10.1007/978-1-4615-2165-5

Jha, A., Patel, A.A., Gopal, T.K. and Nagarajarao, R.C. (2011). Development of a process for manufacture of long-life dairy dessert kheer and its physicochemical properties. International Journal of Dairy Technology, 64(4), 591-597. https://doi.org/10.1111/ j.1471-0307.2011.00713.x

Kaczmarczyk, M.M., Miller, M.J. and Freund, G.G. (2012). The health benefits of dietary fiber: beyond the usual suspects of type 2 diabetes mellitus, cardiovascular disease and colon cancer. Metabolism, 61(8), 1058-1066. https:// doi.org/10.1016/j.metabol.2012.01.017

Kaur, S. (2011). Technology for quality improvement and potential utilization of cereal brans. Ludhiana: Punjab Agricultural University, PhD. Dissertation.

Larmond, E. (1977). Laboratory methods for sensory evaluation of food. Ottawa: Agriculture Canada, Research Branch.

Mukhekar, A., Desale, R. and Shelke, M. (2019). Studies on sensory evaluation and cost of production of rice kheer. The Pharma Innovation Journal, 8(1), 65-67.

Narwade, S.G., Patil, G.R., Sontakke, A.T. and Patil, R.A. (2003). Preparation of kheer from safflower milk blended with buffalo milk. Indian Journal of Dairy Science, 56(4), 197-202.

Ojha, P. and Thapa, S. (2017). Quality evaluation of biscuit incorporated with mandarin peel powder. Scientific Study and Research: Chemistry and Chemical Engineering, Biotechnology, Food Industry, 18(1), 19-30.

Pitkanen, T., Paakkari, P., Miettinen, I.T., Heinonen, H.T, Paulin, L. and Hanninen, M.L. (2007). Comparison of media for enumeration of coliform bacteria and Escherichia coli in non-disinfected water. Journal of Microbiological Methods, 68(3), 522-529. https://doi.org/10.1016/ j.mimet.2006.10.007

Rather, F.A., Pal, M.A., Khan, S.U. and Jalal, H. (2012). Preparation of ready to mix semolina milk puddingKashmiri Fireen. International Journal of Food Nutrition and Safety, 2(2), 46-54.

Sarode A.R., Khedkar, C.D., Kalyankar, S.D., Patil, M.R., Bajad, D.N., Sarode T.R. and Chavhan, S.J. (2004). Studies on microbiological quality of karad- kheer: a value-added dairy product of Maharashtra. Journal of Dairying, Foods and Home Sciences, 26 (2), 98-101.

Shreeja, K., Devi, S.S., Suneetha, W.J. and Prabhakar, B.N. (2019). Formulation of Payasam with Germinated Buckwheat Milk. International Journal of Current Microbiology and Applied Sciences, 8(2), 948-951.

ijcmas.2019.802.109

Smith, K., Waldron, M., Drackley, J.K., Socha, M. and Overton, T. (2005). Performance of dairy cows as affected by prepartum dietary carbohydrate source and supplementation with chromium throughout the transition period. Journal of Dairy Science, 88(1), 255-263. https://doi.org/10.3168/jds.S0022-0302(05) 72683-7

Srinivasan, M.R. and Anantakrishna, C.P. (1964). Milk Products of India. $1^{\text {st }}$ ed. New Delhi: Indian Council of Agricultural Research.

Usha, R., Menon, L. and Anupama, M. (2010). Formulation and quality assessment of instant dhokla mix with incorporation of pumpkin flour. Journal of Scientific and Industrial Research, 69, 956-960.

Williams, C.L., Bollella, M. and Wynder, E.L. (1995). A new recommendation for dietary fiber in childhood. Pediatrics, 96(5), 985-988. 